\title{
Alternativas existem! Análise da produção científica em dois periódicos brasileiros sobre a docência na Educação Física
}

Marcos Garcia Neira*

\begin{abstract}
Resumo: Considerando que o processo de formação universitária de professores implica na problematização das descobertas angariadas por meio do método científico, buscouse identificar quais as principais contribuições da produção acadêmica brasileira sobre a docência em Educação Física. Para tanto, realizou-se um estudo exploratório a partir dos artigos publicados nos dois principais periódicos brasileiros da área. A análise dos dados permitiu verificar a relevância dos conhecimentos produzidos, sugerindo alternativas para sua inserção nos programas que formam professores.
\end{abstract}

Palavras-chave: Educação Física. Ensino. Conhecimento.

\section{OS CONHECIMENTOS DO PROFESSOR}

Os atuais desafios lançados aos docentes durante o seu trabalho diferem daqueles de outros tempos. A manutenção de um clima ameno na sala de aula e a aprendizagem de conteúdos inquestionáveis bastava para que o profissional fosse reconhecido. Na atualidade, as exigências que recaem sobre o magistério são tantas que já se tornou corriqueiro pensar em professor como alguém que vive em um contínuo processo formativo. Há sempre algo a saber e a descobrir sobre a ação educativa, sobre o trabalho que realiza em sala de aula. O problema é a dificuldade em determinar e capturar os conhecimentos que subsidiam o trabalho pedagógico, que, uma vez dominados pelo professor, fundamentariam uma docência sintonizada com a escola contemporânea. 
A discussão a respeito dos conhecimentos do professor é bastante relevante para o cenário educacional atual. Surge como reflexo de um movimento de profissionalização do ensino que trouxe à tona a necessidade de se discutir questões referentes aos saberes necessários aos docentes para que possam exercer com qualidade a sua profissão.

Embora a evolução da atividade de ensino ao status de profissão tenha se realizado a partir do século XIX, só gradualmente é que esse ofício passou a ser objeto de uma formação sistematizada (PERRENOUD, 2002). Centrada no domínio dos saberes a serem ensinados, aos poucos, e de forma bastante desigual, a formação passou a dar importância ao domínio teórico e prático do processo de ensino-aprendizagem. Segundo o autor, cada vez mais se evidencia que um profissional precisa ser capaz de elaborar conceitos e executá-los durante a sua prática. Isso porque não se pode prever de antemão todos os problemas que surgirão na execução da atividade profissional, e desse modo, suas possíveis soluções deverão ser construídas de imediato. Mas para isso, é necessário dispor de saberes abrangentes que envolvam conhecimentos acadêmicos e os oriundos da experiência.

Posicionar o professor como profissional da educação que mais do que dominar os conteúdos de ensino precisa possuir certos saberes que orientem sua prática, contribui para evidenciar a necessidade de discutir a natureza dos saberes dos professores.

Shulman (1987) parte da hipótese de que o docente tem um conhecimento especializado de cuja construção é protagonista: o conhecimento pedagógico do conteúdo. Mas é preciso também ter outros tipos de conhecimento, o conhecimento específico e o pedagógico geral.

O conhecimento específico se refere aos conteúdos que o professor ensina. É preciso que o docente tenha uma compreensão mínima e básica daquilo que vai ser ensinado, além de ter um bom conhecimento das possibilidades representacionais desses conteúdos. Já o conhecimento pedagógico geral inclui conhecimentos de teorias 
e princípios relacionados aos processos de ensinar e aprender, conhecimentos dos alunos e suas realidades, do contexto de sala de aula, da comunidade, sociedade, currículo etc.

O conhecimento pedagógico do conteúdo é construído constantemente durante o ato educativo e é enriquecido e melhorado com base nos outros tipos de conhecimentos. Tratam-se das representações mais úteis dos conteúdos ensinados, das analogias mais poderosas, exemplos, ilustrações, que tornam a compreensão de tópicos específicos mais fácil ou mais difícil.

Shulman (1987) coloca o conhecimento pedagógico do conteúdo como sendo o único que o professor pode ser considerado o autor, já que é aprendido no exercício profissional. A problematização desse conhecimento no curso de formação inicial é bem restrita, porém, na medida em que o professor vai adquirindo experiência, ele ganha profundidade. Por esse motivo, Mizukami (2004) enfatiza que embora os conhecimentos acadêmicos sejam necessários ao exercício profissional, não são suficientes, visto que o professor aprende também a partir da sua experiência.

Tardif (2002) parece corroborar essa ideia quando aponta a impossibilidade de se dissociar os conhecimentos dos professores de seu trabalho na escola e na sala de aula. A relação do docente com o conhecimento nunca é estritamente cognitiva, é também, mediada pelo trabalho que lhe fornece princípios para enfrentar e solucionar as situações cotidianas.

Uma vez que as instituições que formam professores comumente se concentram na veiculação de conhecimentos científicos, o autor defende sua incorporação à prática docente para que esta se transforme em prática científica. Obviamente, não se trata de uma transposição direta, mas de uma "retradução" em função das condições da experiência diária.

A conclusão de Tardif (2002) é a existência de uma distância crítica entre os saberes da experiência e os saberes adquiridos na formação. Os professores, ao entrarem na sala de aula, descobrem os limites de seus conhecimentos e rapidamente, sentem a 
necessidade de "aprender fazendo", mergulhados na prática e adquirindo a experiência fundamental que os fazem "capazes de ensinar".

O que está em pauta, portanto, é uma concepção de docência que não aprisiona o professor a métodos, princípios e técnicas, nem tampouco, aos conhecimentos científicos adquiridos nos bancos universitários. Entendida como uma prática artística, para Corazza (2006) a docência deriva dos sobressaltos e alegrias de trabalhar nas fronteiras da ciência e arte, da teoria e prática. Que tanto recupera e reformula os saberes dos professores construídos no cotidiano profissional, quanto recria e reinventa a produção acadêmica.

\section{PROBLEMA}

No campo da Educação Física, Borges (2005) denuncia que os docentes tendem a questionar os conhecimentos transmitidos durante a formação inicial. Alguns chegam a uma rejeição completa, outros os reavaliam e, finalmente, há aqueles que os analisam com mais nuanças, evidenciando os aspectos que consideram úteis ao exercício profissional.

Tendo em vista a preocupação com uma formação docente cada vez mais coerente com as demandas do exercício profissional, a captura criteriosa dos conhecimentos pedagógicos dos conteúdos ou da experiência a fim de sistematizá-los e valorizá-los nos currículos das instituições responsáveis pela formação de professores poderá constituir-se em uma alternativa interessante.

Atenta à problemática, após ouvir repetidas queixas dos professores em atuação com respeito à distância entre o que lhes foi ensinado na universidade e aquilo de que necessitam para exercer a profissão, Borges (2005, p.186) disparou: "Não é tempo então, de repensar essa formação à luz das exigências da prática dos docentes de profissão?" . 
As respostas têm surgido em formatos variados. Souza Neto, Alegre e Costa (2006) recomendam a aproximação dos licenciandos com a práxis durante os estágios supervisionados e os momentos de prática como componente curricular. Molina Neto e Molina (2009) sugerem que as pesquisas sejam feitas com o professorado baseandose na relação entre a formação e a investigação da prática pedagógica, a fim de possibilitar a constituição da autonomia e a melhoria da qualidade de educação. E, finalmente, Neira (2009) propõe que o currículo da Licenciatura problematize a produção científica que focaliza trabalho pedagógico.

Em sua investigação sobre os currículos que formam professores de Educação Física, o autor constatou o menosprezo acadêmico com relação às disciplinas que abordam a temática escolar. Além do espaço reduzido quando comparado às demais, o tratamento dos conhecimentos referentes à docência deixa a desejar em termos de rigor e profundidade. A combinação de um ambiente informal durante as aulas, o excesso de vivências corporais propostas e a adoção prioritária de textos não científicos contribui para socializar representações distorcidas acerca do ensino e da escola. Para reverter o quadro, defende que os futuros professores sejam, desde seu ingresso na universidade, confrontados com noções do exercício profissional baseadas em conhecimentos científicos.

Caso aceitem a premissa, caberá aos docentes a tarefa de reorganizar o currículo da instituição formativa mediante a adoção de uma postura investigativa com relação ao conhecimento a ser veiculado. As temáticas de estudo não podem simplesmente figurar no currículo universitário devido à tradição. É necessário que os formadores sejam, eles também, estudiosos compromissados com a Educação Física escolar, que mergulhem nesse locus para, recorrendo a métodos de pesquisa, apreendam criticamente as múltiplas dimensões do cotidiano escolar. O que se propõe é o mínimo necessário para elaboração de atividades de ensino coerentes com uma visão contemporânea da educação. 
É importante que se proponham análises criteriosas dos conhecimentos produzidos sobre e na sala de aula, uma vez que só serão realmente colocados em prática na medida em que os professores se sintam seguros o suficiente para desenvolver seu trabalho. Desse modo, parece óbvio sugerir que os pesquisadores trabalhem de maneira integrada às escolas e que os profissionais que lá atuam sejam vistos como colaboradores e co-pesquisadores, e não como objetos a serem investigados.

Para que a distância que separa a produção de conhecimentos da docência em Educação Física possa ser reduzida, os produtos precisam estabelecer relações profícuas e visíveis com o cotidiano. O tempo e recursos gastos na produção de conhecimentos só terão sentido caso contribuam para minimizar os problemas e aperfeiçoar as boas práticas existentes. Afinal, a razão de ser da investigação é a produção de benefícios para todos.

Com o intuito de colaborar no processo de análise da produção acadêmica disponível sobre a docência em Educação Física visando fornecer elementos para que os professores formadores selecionem de maneira mais criteriosa os conhecimentos científicos, para melhor edificar os currículos formativos, desenvolveu-se o presente estudo exploratório. Perseguindo os rastros de Antunes et al. (2005) e Kirk (2010) com um olhar diferenciado, buscou-se identificar as principais contribuições das pesquisas brasileiras acerca do tema e propor alternativas para sua inserção nos programas de formação de professores.

\section{Método}

Sem desconsiderar outros lugares e veículos, partiu-se do pressuposto de que as revistas arbitradas constituem-se em um ambiente qualificado para divulgação dos conhecimentos produzidos mediante critérios de rigor e fidedignidade, quer seja no âmbito dos programas de pós-graduação espalhados pelo país ou nos restritos grupos de pesquisa com o foco na temática. 
Para selecionar o referencial empírico, realizou-se um estudo exploratório nos moldes propostos por Alves-Mazzotti e Gewandsznajder (1998). A pesquisa bibliográfica foi adotada como procedimento. No entendimento de Lima e Mioto (2007), isso significa realizar um movimento incansável de apreensão dos questionamentos e de interlocução crítica com o material bibliográfico.

Considerando a Educação Física enquanto a área de conhecimento, a consulta ${ }^{1}$ ao Portal de Periódicos da Coordenadoria de Aperfeiçoamento do Pessoal de Nível Superior (CAPES) permitiu selecionar os dois periódicos nacionais mais bem avaliados que socializam conhecimentos científicos acerca da prática pedagógica: a Revista Motriz e a revista Movimento, ambas disponíveis para acesso público em formato eletrônico.

A Revista Motriz é uma publicação trimestral do Departamento de Educação Física do Instituto de Biociências da Universidade Estadual Paulista, campus de Rio Claro (SP) e a Movimento, de periodicidade trimestral pertence à Escola de Educação Física da Universidade Federal do Rio Grande do Sul.

À época da coleta ${ }^{2}$, a Revista Motriz havia disponibilizado 28 números da sua publicação em seu sítio na Internet, compreendendo o período de 2003 a 2010 e perfazendo um total de 379 artigos. O emprego dos mecanismos de busca presentes no portal a partir dos descritores "aprendizagem", "currículo", "docente", "educação", "ensino", "escola", "escolar" e "pedagogia" possibilitou a reunião de 44 produtos, abarcando variadas facetas sobre a docência em Educação Física. No portal da revista Movimento estavam disponíveis todos os 43 números publicados entre 1994 e 2010. A repetição do procedimento anterior permitiu agrupar, do montante de 390 artigos, 53 referentes ao tema.

${ }^{1}$ Realizada em dezembro de 2010.

${ }^{2} \mathrm{~A}$ coleta ocorreu nos meses de abril e maio de 2010.

Movimento, Porto Alegre, v. 18, n. 01, p. 241-257, jan/mar de 2012. 


\section{Resultados e discussão}

A leitura dos 97 artigos procurou identificar o objetivo de cada estudo, o método de pesquisa empregado e as descobertas angariadas. A análise do material permitiu a categorização e elaboração de tabelas discriminando a sua incidência quantitativa. Os resultados foram submetidos à interpretação, mantendo como pano de fundo a preocupação com a eventual contribuição para a formação de professores de Educação Física.

Tabela 01 - Objetivos das pesquisas

\begin{tabular}{l|c}
\hline Objetivos & $\%$ \\
\hline Avaliação de propostas decorrentes de hipóteses dos autores & 16,5 \\
\hline Crítica às propostas em vigor na escola & 23,7 \\
\hline $\begin{array}{l}\text { Verificação da contribuição da Educação Física para aquisição ou melhoria de } \\
\text { comportamentos variados }\end{array}$ & 5,1 \\
\hline Mapear a realidade & 54,7 \\
\hline
\end{tabular}

Corroborando as impressões de Antunes et al. (2005), os dados indicam que os pesquisadores têm grande interesse em conhecer o que acontece na escola. Suas preocupações abrangem um leque bastante amplo de assuntos. Wenetz e Stigger $(2006)^{3}$, por exemplo, abordam as relações de gênero; Amaral e Diniz (2009) perspectivam a avaliação nas escolas tradicional e ciclada; e Oliveira e Daolio (2010) quiseram entender como as diferenças são significadas nas aulas de Educação Física.

Nota-se a sensibilidade dos investigadores às dificuldades enfrentadas pelos docentes no cotidiano escolar. Muitas vezes, os dilemas são claramente apontados e utilizados como justificativa para realização das pesquisas. Os trabalhos que proporcionaram a construção desta categoria apontam majoritariamente os flagelos da profissão. Machado et al. (2010), ao analisarem as práticas de desinvestimento pedagógico, ou Melo e Ferraz (2007), quando denunciam o anacronismo presente nas aulas do Ensino Médio, em 
certa medida, desestabilizam as noções tão propagadas pelo senso comum que afirmam ser a Educação Física a disciplina preferida dos estudantes.

Muitos estudiosos não pouparam críticas com relação ao trabalho desenvolvido nas escolas. Elaboradas com rigor e profundidade, as críticas à prática pedagógica do componente contribuem para desvelar elementos ideológicos ocultos ou procedimentos antidemocráticos viciados.

Embora de menor incidência, os experimentos pedagógicos realizados contribuem significativamente para modificação de paradigmas enrijecidos. As análises de Molina Neto (2000) acerca do trabalho com as técnicas esportivas; Neira (2007) com relação à incorporação da cultura corporal popular no currículo; Freire e Santana (2007) sobre uma proposta baseada em jogos; Schiavon e Piccolo (2007) cujo foco recaiu na ginástica escolar; Pérez Lopez et al. (2003), ao proporem uma intervenção orientada para a saúde; e Oliveira (2000) quando propõe e desenvolve ações específicas no Ensino Médio noturno, desmontam os repetitivos discursos sobre a impossibilidade de mudar o que se vem fazendo em função dos obstáculos que a realidade apresenta.

Tabela 02 - Métodos empregados

\begin{tabular}{l|c}
\hline Métodos & $\%$ \\
\hline Pesquisa bibliog ráfica & 24,8 \\
\hline Observações ou entrevistas & 20,7 \\
\hline Pesquisa descritiva & 19,6 \\
\hline Etnografia & 11,3 \\
\hline Pesquisa-ação & 18,5 \\
\hline Análise de discurso & 1,0 \\
\hline Estudo de caso & 4,1 \\
\hline
\end{tabular}

Observa-se, mediante as categorias elaboradas, que embora os pesquisadores diversifiquem os métodos utilizados, há que se considerar uma grande incidência de trabalhos teóricos. Outro aspecto que merece atenção é a menção aos instrumentos utilizados (observações ou entrevistas), sem maiores preocupações com a fundamentação do método de pesquisa. Job, Matos e Trindade (2009), 
ao investigarem uma quantidade significativa de pareceres emitidos pelos avaliadores da revista Movimento, revelaram que as questões de cunho metodológico são responsáveis por uma parcela considerável da recusa dos artigos submetidos.

Apesar do recente trabalho de Lankshear e Knobel (2008) ter atualizado o debate em torno da pesquisa pedagógica, os investigadores responsáveis pelos estudos analisados parecem enfrentar os dilemas da docência em Educação Física a partir de procedimentos investigativos convencionais. É o que se pode interpretar da quase ausência de métodos inspirados na fenomenologia, hermenêutica, construcionismo social, interacionismo simbólico, bricolagem etc. Cabe, portanto, concordar com Alves (2009) quando afirma que é preciso ousar mais no que concerne à pesquisa qualitativa em Educação Física.

Em função das restrições de laudas para publicação, a maioria dos trabalhos analisados discorre rapidamente sobre os procedimentos empregados. Poucos informam sobre as condições de coleta, as especificidades dos instrumentos e as técnicas de análise. Os deslizes metodológicos podem ser verificados nas etnografias apressadas, tal qual sinaliza André (2000), nas pesquisas-ação por interesse único do proponente, conforme denuncia Franco (2005) e na ausência da delimitação do campo para realização das descrições, requisito fundamental conforme apontam Alves-Mazzotti e Gewandsznajder (1998).

Tabela 03 - Descobertas

\begin{tabular}{l|l}
\hline Descobertas & $\%$ \\
\hline $\begin{array}{l}\text { Incitar mudanças curriculares (planos e/ou métodos e/ou conteúdos e/ou } \\
\text { avaliação) }\end{array}$ & 41,3 \\
\hline Ampliar a compreensão sobre o que acontece nas aulas & 35,0 \\
\hline Ampliar a compreender a respeito dos sujeitos da Educação Física & 23,7 \\
\hline
\end{tabular}

A leitura atenta do material recolhido permite vislumbrar diferentes contribuições para melhoria da prática pedagógica da Educação Física. Grande parte das investigações incitam mudanças curriculares. Impolcetto e Darido (2007) sugerem que o trabalho com o tema transversal ética seja implementado nas aulas do 
componente; Coelho (2009) discute o uso das tecnologias de comunicação e informação; Vendruscolo (2009) apresenta o circo como possibilidade temática; Hirai e Cardoso (2009) recomendam ações didáticas baseadas na problematização; Tavares (1995) propõe a interdisciplinaridade. Esta é uma amostra das infinitas possibilidades de incremento do currículo da Educação Física. A produção acadêmica analisada é bem diversificada, sugerindo a adoção de princípios pedagógicos, temas, conteúdos, métodos de ensino, instrumentos de avaliação, além de novos olhares para tudo aquilo que possa ser do domínio dos professores em atuação.

O montante de estudos que se debruçaram sobre o que acontece nas aulas permitiu identificar aspectos que merecem ser ressaltados (RIBEIRO; MARIN, 2009), assim como, aqueles que, a partir da sua sinalização, poderão ser modificados (BASSANI; TORRI; VAZ, 2003).

Finalmente, um conjunto bem interessante de artigos contribui para ampliar a compreensão dos sujeitos da Educação Física. Mesmo reconhecendo que diversos atores interferem diretamente processo educativo (familiares, equipe gestora, outros profissionais da escola e a comunidade mais ampla), foram identificados trabalhos que analisaram especificamente os professores, os alunos e, principalmente, as relações presentes nas aulas. Observou-se, também, uma mudança na tendência apontada por Antunes et al. (2005). Os trabalhos atentos à escola como ambiente de profissionalização docente (MOLINA NETO, 2003) começam a dividir espaço com estudos pautados nas relações de gênero (FALKENBACH et al., 2007) e na inclusão (LIMA, 2005).

\section{Considerações}

Inversamente aos resultados encontrados por Antunes et al. (2005), embora sua amostra tenha incluído publicações nacionais e internacionais, os dados indiciam uma grande preocupação dos pesquisadores acadêmicos com o que acontece no âmbito da 
Educação Física escolar e, indo além, tecem recomendações bastante plausíveis. Nesse sentido, corroboram os achados de Kirk (2010), mesmo que restritas a publicações europeias.

As análises realizadas levam a inferir que a produção científica relativa à docência em Educação Física denota sensibilidade às problemáticas que afligem o cotidiano escolar. Mantendo acesa a chama da esperança de uma Educação Física melhor, os autores dos trabalhos publicados nas Revistas Motriz e Movimento não se cansam de experimentar propostas, analisar as existentes e sugerir encaminhamentos. Não se está propondo a aceitação passiva das recomendações advindas da academia. Qualquer sugestão necessita de criticidade e uma certa relativização.

Os dados também remetem à preocupação de investigar aqueles que fazem o cotidiano pedagógico. Um conhecimento mais profundo dos processos vividos pelo professor ao longo do seu percurso profissional possibilitará a proposição de políticas específicas que lhe deem o suporte necessário em diversas instâncias, dentro e fora da escola. É fundamental que os mecanismos de profissionalização, ou seja, as agruras e benesses vividas pelos docentes sejam discutidas desde a formação inicial. A consciência dos fatores que influem na realização da ação educativa poderá ser alcançada antes que seu efetivo exercício se inicie. Consequentemente, será mais fácil encontrar alternativas para solução dos dilemas a serem enfrentados.

O mesmo se pode dizer da importância do debate, desde os bancos universitários, sobre as relações sociais na escola e nas aulas de Educação Física. As questões de gênero e inclusão são apenas alguns dos temas discutidos pelos pesquisadores que precisam ser urgentemente incorporados aos currículos da Licenciatura.

Os métodos utilizados, conforme se observou, mostram-se parcialmente divorciados do espírito que envolveu a maioria dos trabalhos. Dentre os estudos que pretendiam descrever e analisar a ocorrência de um certo fenômeno nas aulas de Educação Física (conflitos de gênero, indisciplina, desinteresse dos alunos etc.), foram identificados os que se perderam em repetições do conteúdo presente 
em trabalhos teóricos, dedicando pouco espaço à descrição e análise das observações. Movidos por intenções nobres, é verdade, pesquisadores realizaram tentativas de modificação das práticas docentes e discentes sem atentar para um elemento primário nessa modalidade investigativa - o interesse e a intenção de mudança dos sujeitos envolvidos. Além dos muitos casos em que os procedimentos metodológicos adotados não mencionaram a forma de análise do material recolhido, verificou-se que em alguns estudos a discussão dos dados se deu na ausência do confronto com o referencial teórico.

Isso significa que as questões metodológicas precisam receber mais atenção nos programas de formação. Sugere-se que a abordagem dos conhecimentos científicos nas salas de aula seja acompanhada da explicitação do método de investigação utilizado. Na medida do possível, seria recomendável transformar a sistemática de produção de conhecimentos em objeto de estudo, posto que é impossível formar bons professores na ausência de uma postura crítica com relação ao modo como os conhecimentos são elaborados.

Enfim, o debruçar sobre a produção científica que abarca a docência em Educação Física trouxe à tona suas diversas contribuições. Algo que vinha sendo persistentemente ocultado pelos setores que insistem em menosprezar o papel da universidade no encaminhamento de alternativas viáveis aos desafios enfrentados no cotidiano escolar. As análises revelam que a pesquisa acadêmica mantém-se alerta e sintonizada com as demandas docentes, o que permite assegurar a necessidade da sua continuidade e ampliação, bem como do incentivo à divulgação dos resultados. Todavia, os fatores que têm obstaculizado uma incorporação mais efetiva dos novos conhecimentos aos currículos que formam professores merecem atenção e urgente solução. 
Alternatives exist: analysis of scientific literature in two Brazilian journals about the pedagogical work of Physical Education

Abstract: Considering that the process of teacher training in universities takes into account the confrontation of knowledge produced by the scientific methods, the current study intended to identify what are the main contributions of the Brazilian scientific production of Physical Education teaching. Therefore, an exploratory study was done from the articles published on the subject in the two main periodicals of the area. The data analyzes allowed us to verify the relevancy of the knowledge produced and to suggest alternatives to its inclusion in the docent training programs.

Keywords: Physical Education. Teaching. Knowledge.

¡Alternativas existen! Análisis de la producción científica em dos revistas brasileñas acerca de la enseñanza en Educación Física

Resumen: Una vez que el proceso de formación universitária de profesores supone la problematización de lo que ha sido apuntado a través del método científico, se intentó identificar cuáles son las principales contribuciones de la producción académica acerca de la enseñanza en Educación Física. Así, se han investigado artículos publicados en los dos principales periódicos brasileños del área. El análisis de los datos identifico la relevancia de los conocimientos producidos y sugieren alternativas para su inserción en los programas de formación de profesores.

Palabras clave: Educación Física. Enseñanza. Conocimiento.

\section{REFERÊNCIAS}

ALVES, F. S. Pesquisa qualitativa: desbravando territórios possíveis de se fazer ciência. Revista Motriz. Rio Claro, v. 15. n. 4, p. 955-963, 2009.

ALVES-MAZZOTTI, A. J.; GEWANDSZNAJDER, F. O método nas ciências naturais e sociais: pesquisa quantitativa e qualitativa. São Paulo: Pioneira, 1998.

Movimento, Porto Alegre, v. 18, n. 01, p. 241-257, jan/mar de 2012. 
AMARAL, S. C. F.; DINIZ, J. A avaliação na Educação Física escolar: uma comparação entre as escolas tradicional e ciclada. Movimento, Porto Alegre, v. 15, n. 01, p. 241-258, 2009.

ANDRÉ, M. Etnografia da prática escolar. Campinas: Papirus, 2000.

ANTUNES, F. H. C. et al. Um retrato da pesquisa brasileira em Educação Física escolar: 1999 - 2003. Revista Motriz. Rio Claro, v. 11, n. 3, p. 179-184, 2005.

BASSANI, J. J.; TORRI, D.; VAZ, A. F. Sobre a presença do esporte na escola: paradoxos e ambiguidades. Movimento, Porto Alegre, v. 09, n. 02, p. 89-112, 2003.

BORGES, C. A formação dos docentes de Educação Física e seus saberes profissionais. In: BORGES, C.; DESBIENS, J. F. (Orgs.) Saber, formar e intervir para uma Educação Física em mudança. Campinas: Autores Associados, 2005.

COELHO, C. R. B. Tecnologias da comunicação e informação na Educação Física infantil. Revista Motriz, Rio Claro, v. 14, n. 03, p. 339-345, 2008.

CORAZZA, S. M. Artistangens: Filosofia da diferença e educação. Belo Horizonte: Autêntica, 2006.

FALKENBACH, A. P. et al. A inclusão de crianças com necessidades especiais nas aulas de Educação Física na Educação Infantil. Movimento, Porto Alegre, v. 13, n. 02, p. 37-53, 2007.

FRANCO, M. A. S. Pedagogia da pesquisa-ação. Educação e pesquisa, São Paulo, v. 31, n. 3, p. 483-502, set./dez. 2005.

FREIRE, J. B.; SANTANA, G. N. L. Relações sociais no desenvolvimento da imaginação por meio dos jogos. Revista Motriz, Rio Claro, v. 13, n. 04, p. 249-258, 2007.

GOODSON, I. F. Currículo: teoria e história. Petrópolis: Vozes, 2002.

HIRAI, R. T.; CARDOSO, C. L. Possibilidades para o ensino orientado na problematização: para a realização da concepção de "aulas abertas às experiências". Movimento, Porto Alegre, v. 15, n. 01, p. 99-116, 2009.

IMPOLCETTO, F. M.; DARIDO, S. C. Ética como tema transversal: possibilidades de aplicação nas aulas de Educação Física escolar. Revista Motriz, Rio Claro, v. 13, n. 1, p. 14-23, 2007.

JOB, I.; MATTOS, A. M.; TRINDADE, A. Processo de revisão pelos pares: por que são rejeitados os manuscritos submetidos a um periódico científico? Movimento, Porto Alegre, v. 15, n. 03, p. 335-355, 2009.

KIRK, D. O porquê de investigar: estado atual e tendências futuras nas pesquisas em Educação Física. Movimento, Porto Alegre, v. 16., n. 02, p. 11-43, 2010. 
LANKSHEAR, C.; KNOBEL, M. Pesquisa pedagógica: do projeto à implementação. Porto Alegre: Artmed, 2008.

LIMA, M. S. C. O diverso, o diferente e o idêntico no contexto escolar: o que dizem os discursos oficiais das políticas públicas de inclusão? Movimento, Porto Alegre, v. 11, n. 03, p. 183-198, 2005.

LIMA, T. C. S.; MIOTO, R. C. T. Procedimentos metodológicos na construção do conhecimento científico: a pesquisa bibliográfica. Revista Katálysis, Florianópolis, v. 10, n. esp. p. 37-45, 2007.

MACHADO, T. S. et. al. As práticas de desinvestimento pedagógico na Educação Física escolar. Movimento, Porto Alegre, v. 16, n. 02, p. 129-147, 2010.

MELO, R. Z.; FERRAZ, O. L. O novo ensino médio e a Educação Física. Revista Motriz. Rio Claro, v. 13, n. 2, p. 86-96, 2007.

MIZUKAMI, M. G. N. Aprendizagem da docência: algumas contribuições de L.S. Shulman. Revista do Centro de Educação, v. 29, p. 1-13, 2004.

MOLINA NETO, V. Uma experiência de ensino do futebol no currículo de licenciatura em Educação Física - experiência no 2. Movimento, Porto Alegre, v. 6, n. 12, 2000. p. 53-62.

MOLINA NETO, V. Crenças do professorado de Educação Física das escolas públicas de Porto Alegre. Movimento, Porto Alegre, v. 09, n. 01, 2003. p. 145-169.

MOLINA NETO, V.; MOLINA, R. A prática pedagógica do professorado de Educação Física no cotidiano escolar. In: MOLINA NETO, V. et al. (Orgs.) Quem aprende? Pesquisa e formação em Educação Física escolar. Ijuí: Editora Unijuí, 2009.

NEIRA, M. G. Valorização das identidades: a cultura corporal popular como conteúdo do currículo da Educação Física. Revista Motriz. Rio Claro, v. 13, n. 3, p.174-180, jul./set. 2007.

NEIRA, M. G. Desvelando Frankensteins: interpretações dos currículos de Licenciatura em Educação Física. Revista Brasileira de docência, ensino e pesquisa em Educação Física, Cristalina, v.1., n. 1, p. 118-140, ago. 2009.

OLIVEIRA, A. A. B. A Educação Física no Ensino Médio - período noturno: um estudo participante. Movimento. Porto Alegre, v. 06, n. 12, p. 05-13, 2000.

OLIVEIRA, A. C. S.; RAMOS, Glauco Nunes. Construindo saberes pela formação e prática profissionais de uma professora de Educação Física do Ensino Médio. Revista Motriz, Rio Claro, v. 14, n. 03, p. 252-259, 2008.

OLIVEIRA, R. C.; DAOLIO, J. Educação Física, cultura e escola: da diferença como desigualdade à alteridade como possibilidade. Movimento, Porto Alegre, v. 16, n. 01, p. 149-167, 2010. 
PEREZ LOPEZ, I. J. et al. Um programa de intervenção em Educação Física orientado para a saúde: a avaliação dos alunos. Movimento, Porto Alegre, v. 09, 01, p. 149167, 2003.

PERRENOUD, P. A prática reflexiva no ofício do professor: profissionalização e razão pedagógica. Porto Alegre: Artmed Editora, 2002.

PRADO, V. M.; MATTHIESEN, S. Q. Para além dos procedimentos técnicos: o atletismo em aulas de Educação Física. Revista Motriz, Rio Claro, v. 13, n. 03, p. 120-127, 2007.

RIBEIRO, G. M.; MARIN, E. C. Educação Física escolar: a ação pedagógica e sua legitimação enquanto prática social na escola itinerante do MST. Movimento, Porto Alegre, v. 15, n. 04, p. 35-62, 2009.

SCHIAVON, L.; PICCOLO, V. N. A ginástica vai à escola. Movimento, Porto Alegre, v. 13, n. 03, p. 131-150, 2007.

SHULMAN, L. S. Knowledge and teaching: foundations of the new reform. Harvard Educational Review, v. 01, n. 57, p. 1-22, 1987.

SOUZA NETO, S.; ALEGRE, A. N. ;COSTA, A. A prática como componente curricular e o estágio curricular supervisionado: que rumo tomar? In: SOUZA NETO, S. e HUNGER, D. (Orgs.) Formação profissional em Educação Física: estudos e pesquisas. Rio Claro: Biblioética, 2006.

TARDIF, M. Saberes Docentes e Formação Profissional. Petrópolis, RJ: Vozes, 2002.

TAVARES, M. Uma experiência interdisciplinar nas aulas de Educação Física. Movimento, Porto Alegre, v. 02, n. 03, p. 51-54,1995.

VENDRUSCOLO, C. R. P. O circo na escola. Revista Motriz. Rio Claro, v. 15, n. 03, p. 729-737, 2009.

WENETZ, I.; STIGGER, M. P. A construção do gênero no espaço escolar. Movimento, Porto Alegre, v. 12, n. 01, p. 59-80, 2006.

Apoio: CNPq 
